\title{
Skull fracture vs. accessory sutures: how can we tell the difference?
}

\author{
Thomas Sanchez • Deborah Stewart • \\ Matthew Walvick • Leonard Swischuk
}

Received: 23 March 2010/Accepted: 12 May 2010 / Published online: 23 May 2010

(C) The Author(s) 2010. This article is published with open access at Springerlink.com

Keywords Skull fractures $\cdot$ Accessory sutures $\cdot$ CT scan

\section{Introduction}

Plain film radiography remains the most cost effective method in evaluating skull fractures and can easily differentiate major sutures and common vascular grooves from fractures. However, in children this can be complicated due to the presence of numerous synchondroses and unusual accessory sutures. Plain film evaluation is especially challenging not only because of various artifacts that can degrade the study but also the inability to visualize intracranial processes, such as contusions and hemorrhage, that can substantiate a calvarial finding.

From the Departments of Radiology and Pediatrics, University of California Davis, Sacramento CA and University of Texas Medical Branch, Galveston TX

\section{T. Sanchez $(\square)$}

University of California Davis,

Sacramento, CA, USA

e-mail: thomas.sanchez@ucdmc.ucdavis.edu

D. Stewart

CAARE Diagnostic and Treatment Center,

Department of Pediatrics, University of California Davis,

Sacramento, CA, USA

\section{Walvick}

Department of Internal Medicine,

University of California San Francisco,

Fresno, CA, USA

L. Swischuk

Department of Radiology, University of Texas Medical Branch, Galveston, TX, USA
Minimal soft tissue swelling can be difficult to see even with oblique views. Superimposition of normal suture lines like the metopic suture can mimic a fracture if one is not careful to obtain additional views [1]. During the past decade, the increasing use of spiral and multidetector CT have lead to the ability of workstations to generate threedimensional (3D) reconstructions of the skull. Therefore if cranial CT is deemed clinically necessary in trauma patients, questionable fractures can be confidently differentiated from unusual accessory sutures using these additional workstation capabilities.

\section{Normal ossification centers}

The parietal and occipital bones in particular are common regions for accessory sutures because of their multiple ossification centers. The parietal bone ossifies from two centers while the occipital bone ossifies from six centers [2, 3]. An accessory intraparietal or subsagittal suture is rare but can be seen dividing the parietal bone (Fig. 1). They can be explained on the basis of incomplete union of the two separate ossification centers [4]. These are usually bilateral and fairly symmetrical but can at times be unilateral. The occipital bone has a more complex development. The foramen magnum is surrounded by four ossification centers. On each side are the exoccipitals, ventrally located is the basoccipital and dorsally, the supraoccipital center contains the midline occipital fissure which can sometimes persist antenatally (Fig. 2). This pattern of development can therefore give rise to numerous accessory sutures that could be mistaken for fractures especially with plain film evaluation alone. CT scan with $3 \mathrm{D}$ reconstruction is vital in the further characterization of a questionable fracture. 


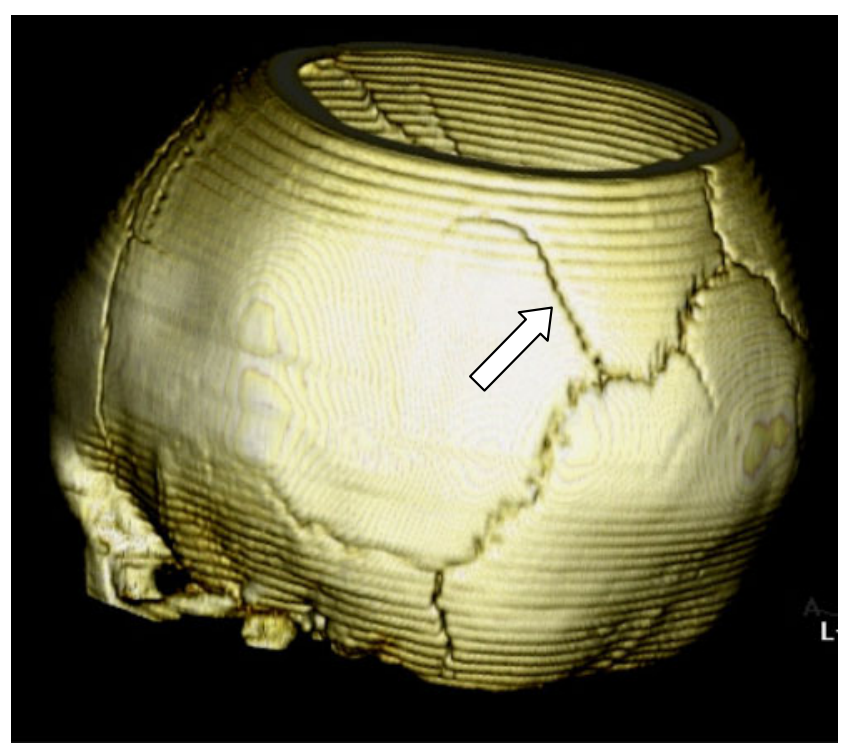

Fig. 1 Accessory intraparietal or subsagittal suture (arrow)

\section{Radiographic differentiation of skull fracture and accessory suture}

Simple non-depressed skull fractures are sharp lucencies with non-sclerotic edges. In contrast, accessory sutures usually will show a zigzag pattern with interdigitations and sclerotic borders similar to major calvarial sutures (Fig. 3). When fractures extend into a major suture, there could be widening of the fracture line as it approaches the suture or there is associated diastasis of the adjacent synchodrosis or suture. (Fig. 4). An accessory suture will usually not produce this appearance. High impact fractures can cross suture lines or extend from one major suture to another, whereas accessory sutures join and merge with the major suture (Fig. 5). In terms of bilaterality, accessory sutures are often present on both sides and are fairly symmetric especially in the parietal bones [2]. Occipital accessory sutures can be complex and multiple but are also frequently bilateral [5]. However, skull fractures can be also bilateral. When they are, these fractures are almost always associated with high impact injuries and thus will often show comminution, depression, and marked asymmetry. Hence, these complex and high impact fractures are almost never confused with developmental variants [6,7]. Finally, soft tissue swelling or hematoma is frequently associated with acute skull fractures. One study has shown that at least $4 \mathrm{~mm}$ of soft tissue swelling was present on the cranial CT scan in all cases of acute skull fractures that they reviewed [8]. However, absence of subgaleal hematoma or swelling does not entirely rule out a fracture especially if the injury is remote or imaging was performed several days after the trauma [9]. Its presence though is highly suggestive of an acute traumatic event. (Fig. 6).

Knowledge of the normal anatomy, development and timing of sutural closure are also important in the evaluation of questionable fractures. The occipital and innominate sutures are no longer apparent by age 4 while
Fig. 2 Three-dimensional reconstruction of the occipital bone outlining the six ossification centers including the remnant of the midline occipital fissure (arrow). Two interparietal ossification centers (yellow), single supraoccipital center (red), two exoccipitals (violet), and single basoccipital (green). $F M$ foramen magnum
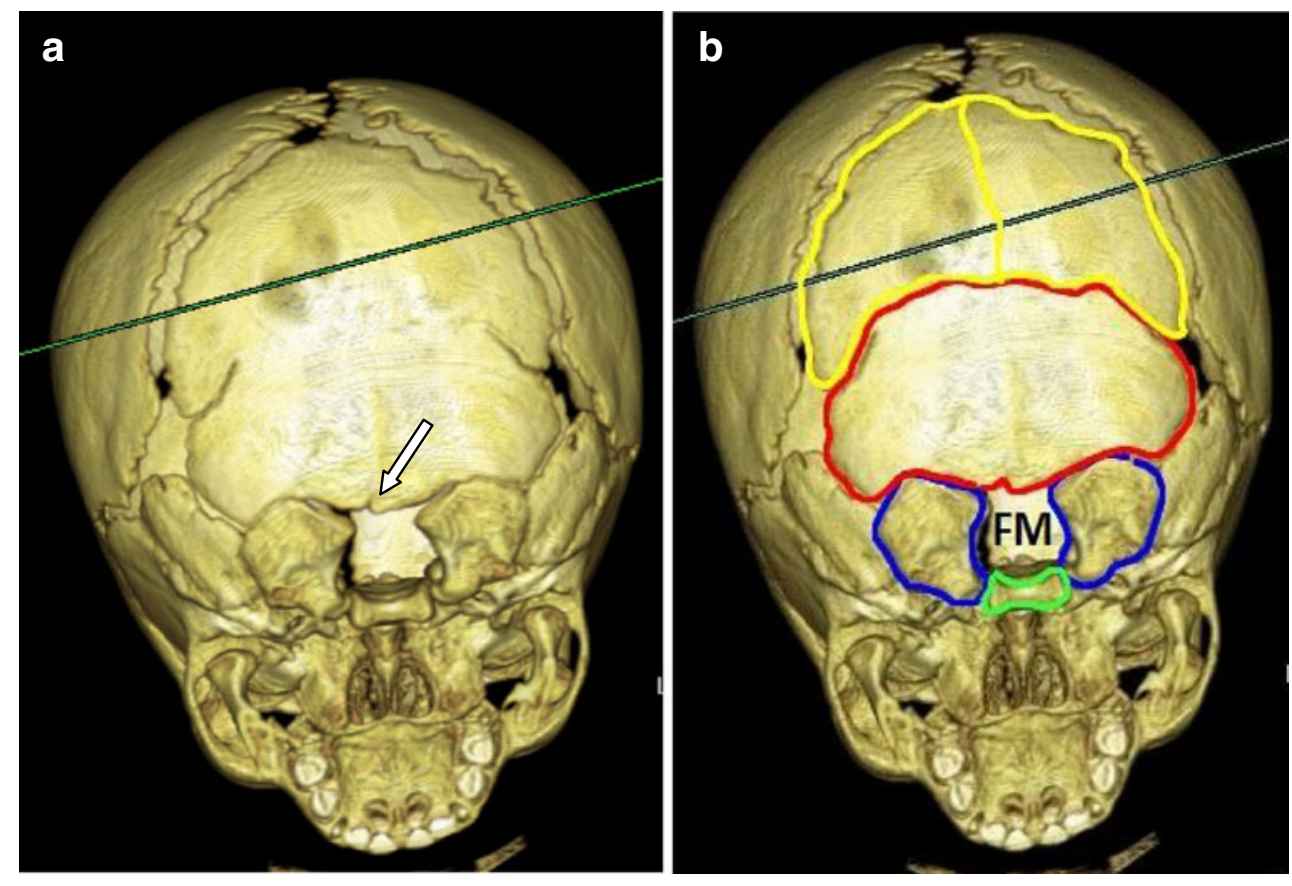


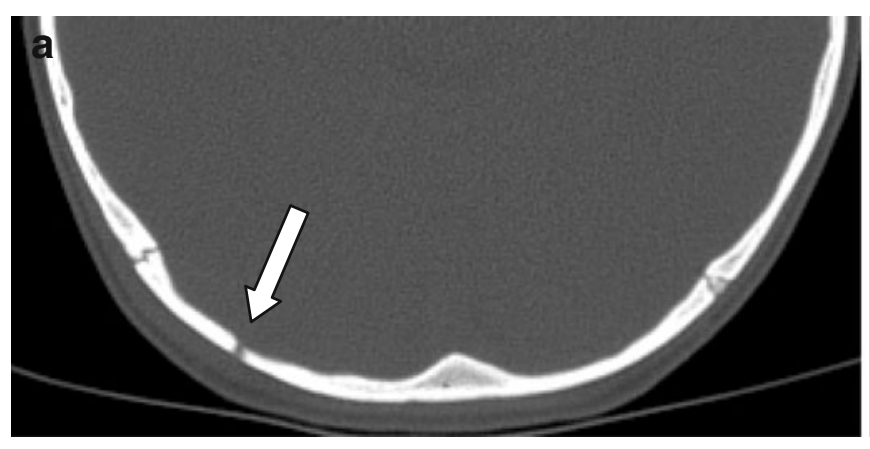

Fig. 3 a This sharp lucency (arrow) with adjacent mild soft tissue swelling represents a fracture. b In contrast, this occipital accessory suture (arrow) has a sclerotic border with irregular interdigitations

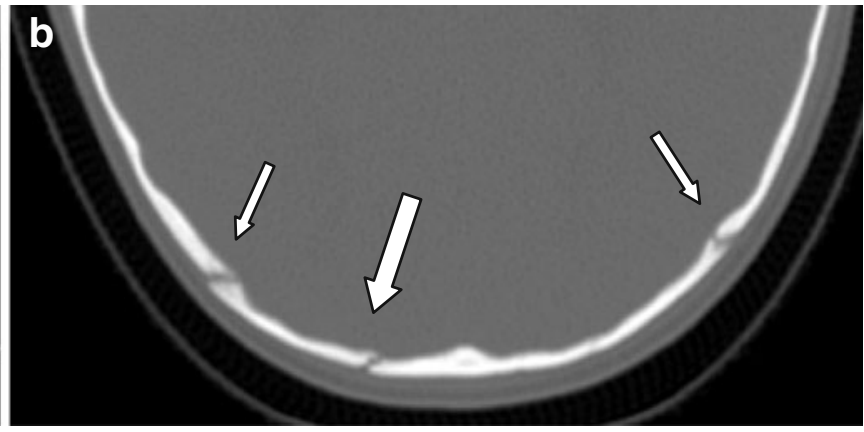

similar to the adjacent lambdoid sutures (smaller arrows). Note the absence of soft tissue swelling
Fig. 4 a Notice how the fracture line is narrow proximally but progressively widens as it extends into the sagittal suture. b In a different patient, the left occipital bone fracture (arrow) extends into and slightly widens the posterior intraoccipital synchondrosis (small arrow)
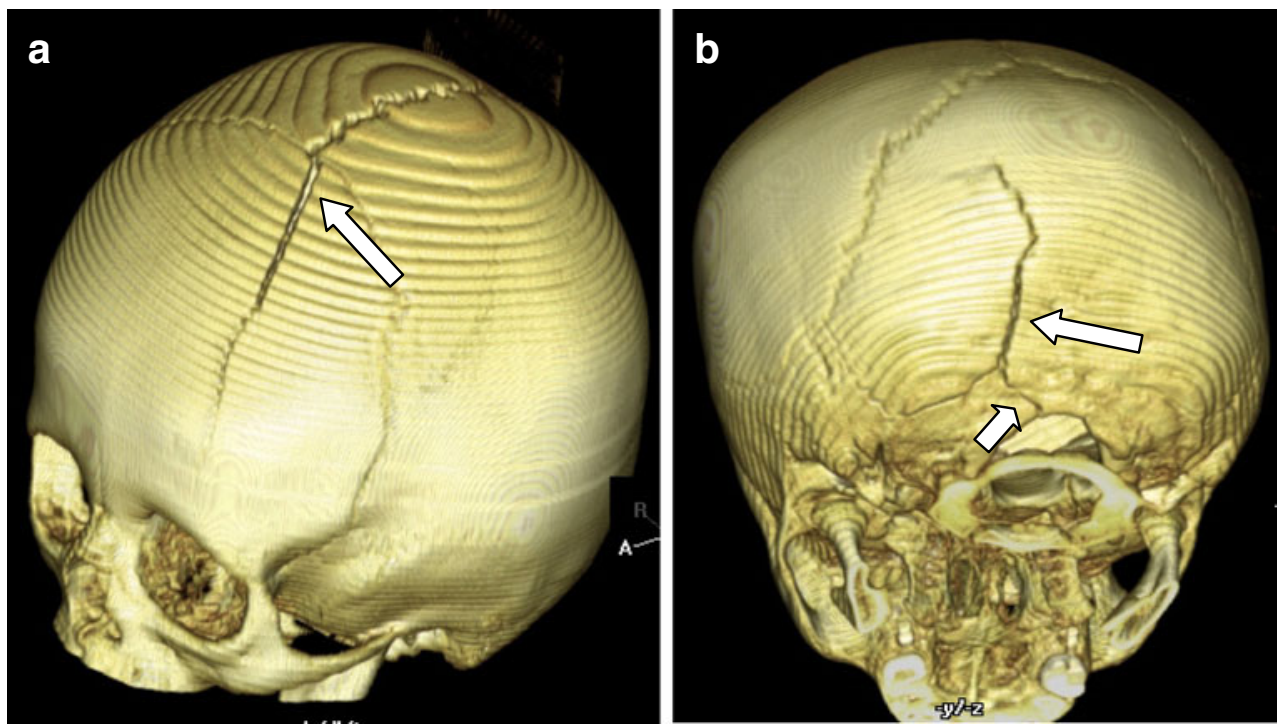

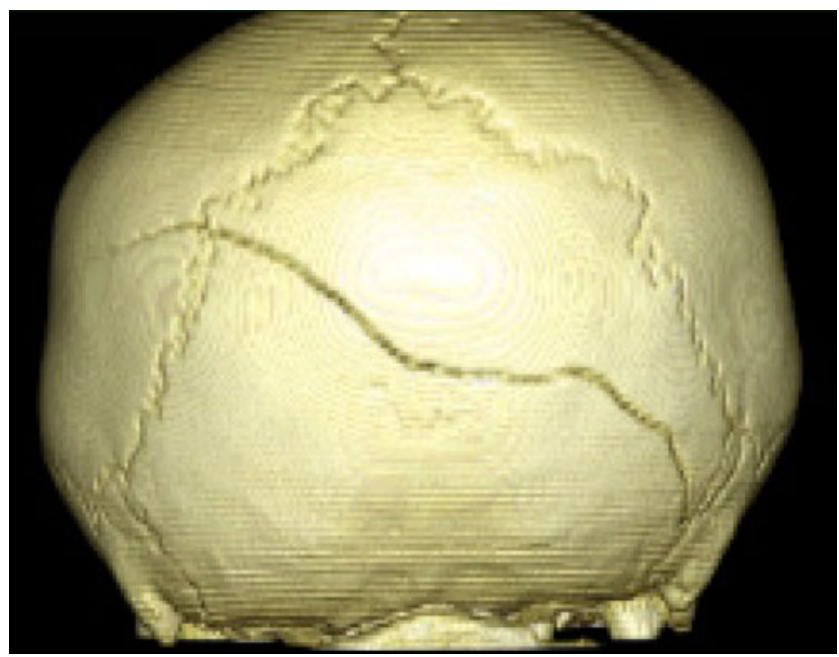

Fig. 5 High impact injury with a non-depressed fracture line extending from both lambdoid sutures and crossing over into the left parietal bone. Accessory sutures will not produce this appearance the mendosal suture completely fuses by 6 years of age [10]. An example of an accessory suture that can be misleading is the normal persistent occipital suture. It extends from the dorsal aspect of the foramen magnum and can appear wide and sharp. However, it should extend no more than $2 \mathrm{~cm}$ from the edge of the foramen magnum. A longer fissure would be inconsistent with its normal embryogenesis and therefore represents a fracture [3] (Fig. 7). In some cases where a lucency is shorter than $2 \mathrm{~cm}$, the age of the patient would help in deciding if this is a fracture or just a sutural remnant. As noted previously, this suture closes by 4 years and a persistent lucency beyond this age is indicative of a fracture.

In some cases, definite differentiation between a fracture and accessory suture can still be elusive. This is illustrated by a recent case where a 2-year-old boy came in with mild frontal soft tissue swelling after a fall. Plain 
Fig. 6 a Sharp lucency representing a fracture in the right parietal region is accompanied by a large subgaleal hematoma (arrow). b In a different patient, the right temporal bone fracture is associated with a more subtle $3 \mathrm{~mm}$ soft tissue swelling (arrow)
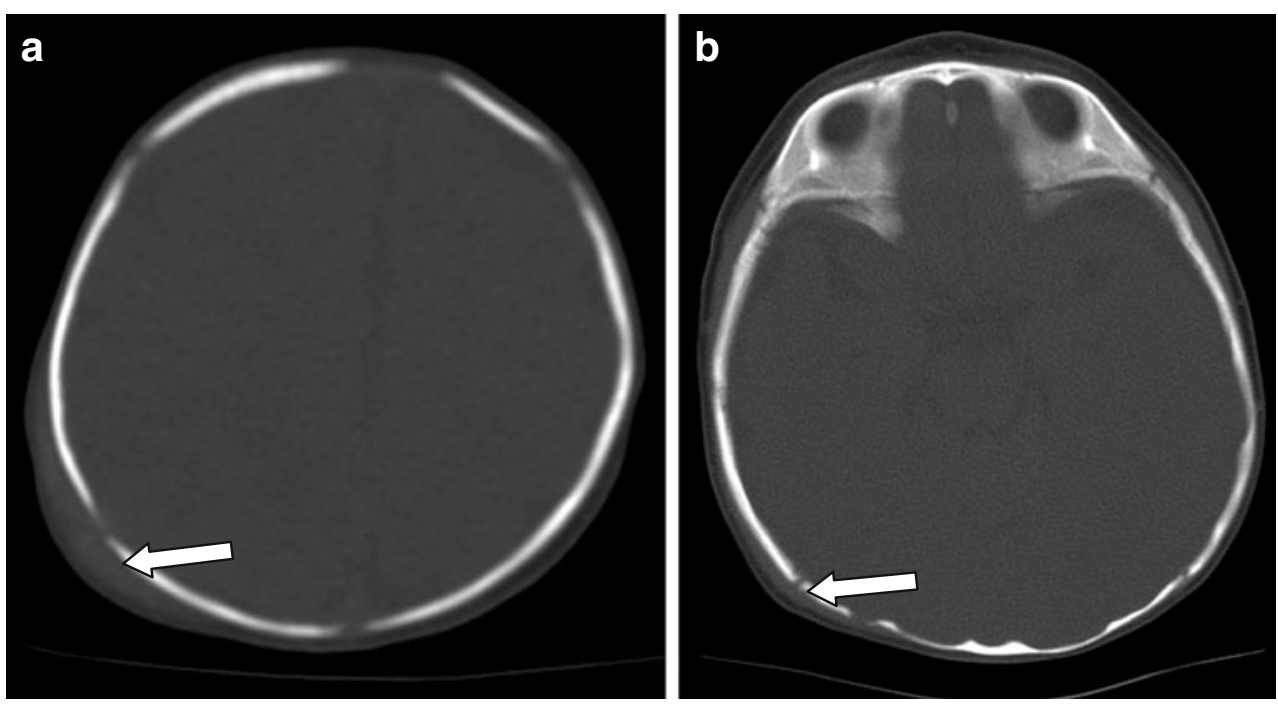

radiograph showed a sharp lucency in the left occipital bone that was thought to represent a fracture. CT scan with 3D reconstruction was performed and showed a well-defined lucency extending into the lambdoid suture. There is no associated diastasis or widening and it does not extend into the foramen magnum posteriorly. Soft tissue swelling or hematoma was also absent. A bone scan was performed which showed no evidence of radiotracer uptake. It was therefore felt that this is more consistent with an accessory suture. Follow-up study after 3 months however showed sclerosis of this lucency indicating that this was indeed a fracture. (Fig. 8). Clinical experience has consistently demonstrated that bone scan is much less sensitive in detecting skull fractures. In one study, less than $40 \%$ of skull scintigrams were positive in patients with clearly visualized fractures in skull radiographs $[11,12]$. The above case also demonstrates that in difficult cases, a follow-up study might be the only way to differentiate a fracture from an accessory suture. A fracture usually will show evidence of healing or sclerosis in two or three months.

\section{Conclusion}

In summary, fractures and accessory sutures can be differentiated in most cases by observing its characteristics

Fig. 7 This midline occipital fracture extending into the foramen magnum is easily differentiated from a normal persistent midline occipital fissure because of its length, extending $3 \mathrm{~cm}$ from the dorsal lip of the foramen magnum

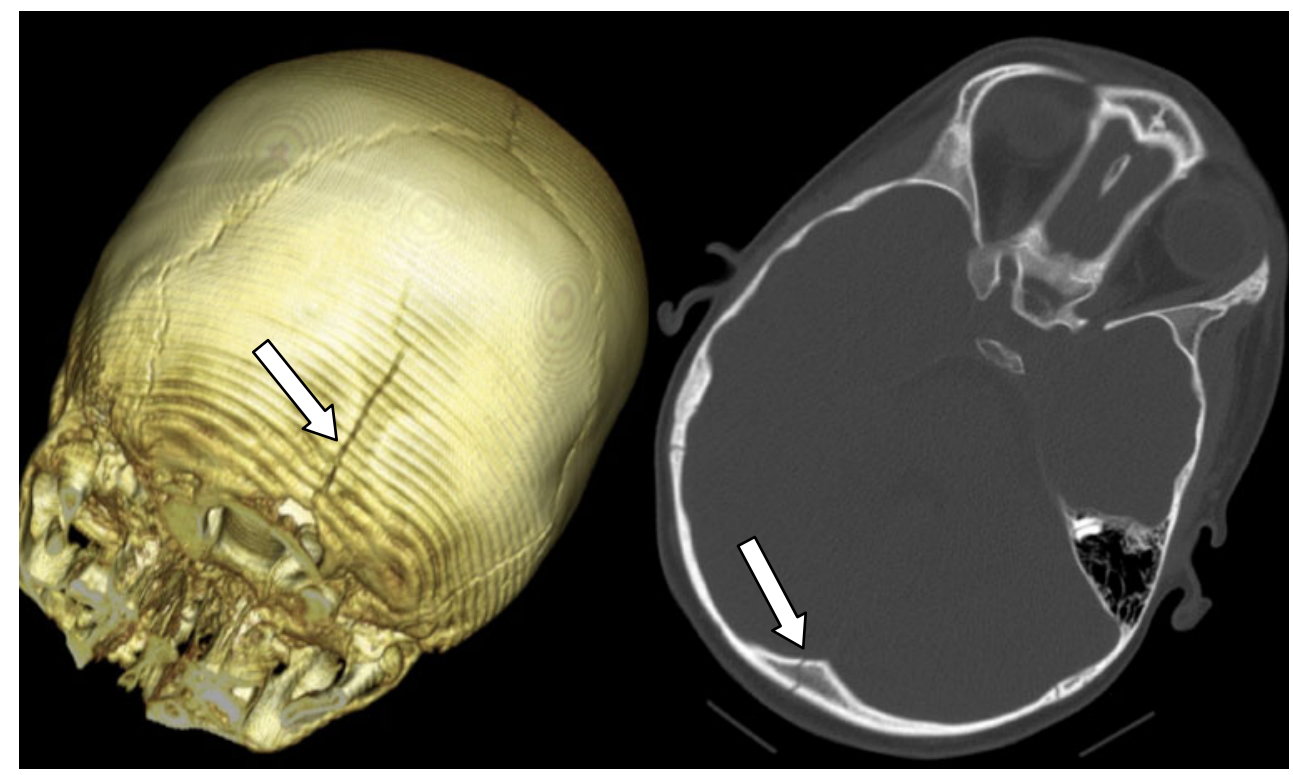


Fig. 8 Occipital fracture that was mistaken for an accesory suture. a Plain radiograph showed a left occipital lucency. b Nuclear medicine study did not show any abnormal uptake of radiotracer. c Together with the CT scan characteristics, it was felt that this lucency is more compatible with an accesory suture. d Follow-up CT scan after 3 months however showed sclerosis of this lucency indicating healing of the fracture
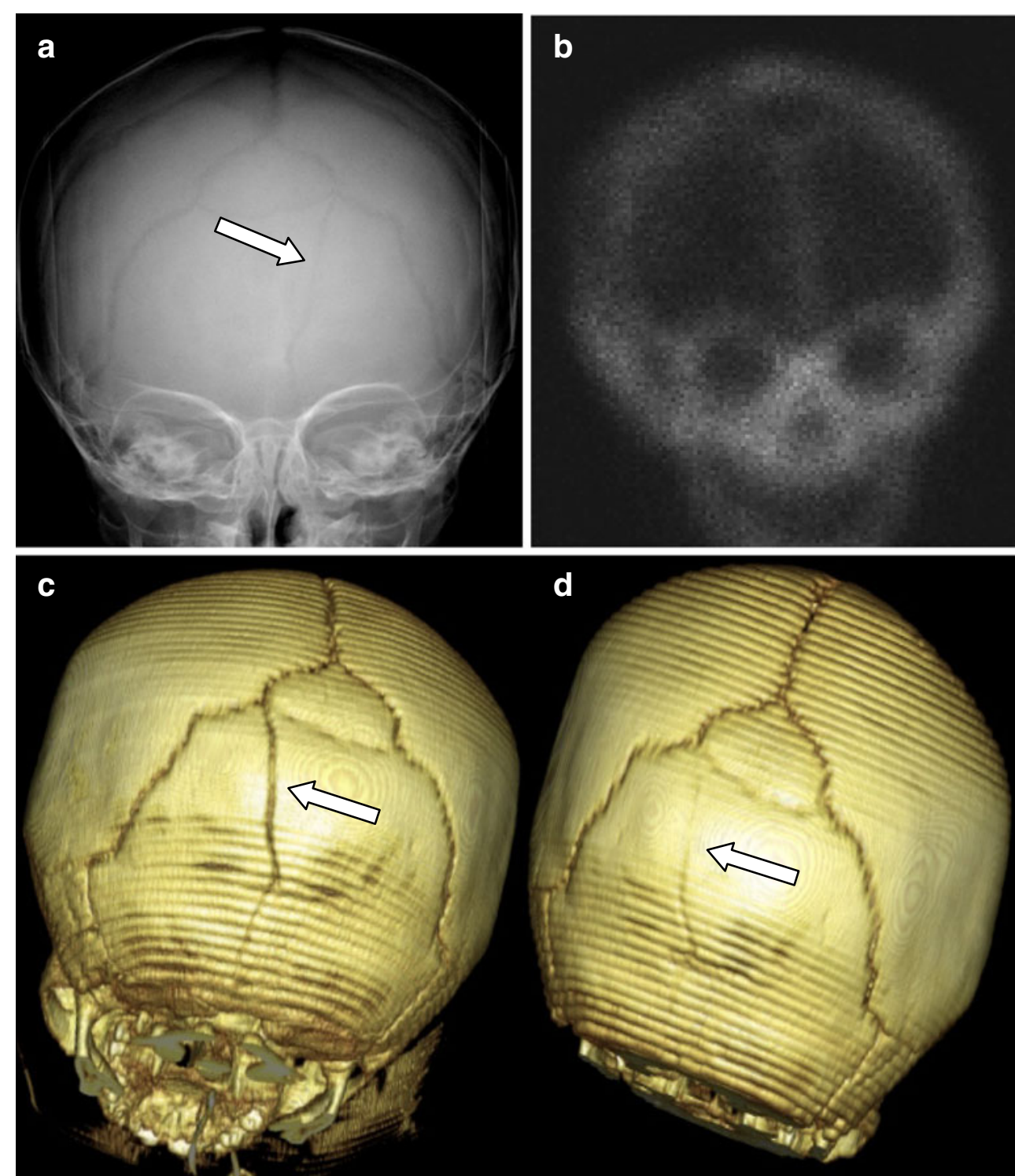

such as bilaterality, symmetry, associated diastasis, and presence of soft tissue swelling (Table 1). Knowledge of the normal anatomy, development, and timing of sutural closure are also necessary to decipher the varied and sometimes complex nature of these accessory sutures especially in the occipital region. However, in difficult cases, it is prudent to request for a follow-up study to look for signs of healing.

Table 1 Differentiation between skull fracture and accessory suture

\section{Skull fracture}

Sharp lucency with non-sclerotic edges

Widens as is approaches a suture

Can cross adjacent suture lines

Often unilateral and asymmetric if bilateral

Associated with some soft tissue swelling
Accessory suture

Zigzag pattern with sclerotic borders No associated diastasis

Merges with the adjacent suture

Often bilateral and fairly symmetric

No soft tissue swelling 
Open Access This article is distributed under the terms of the Creative Commons Attribution Noncommercial License which permits any noncommercial use, distribution, and reproduction in any medium, provided the original author(s) and source are credited.

\section{References}

1. Chasler C (1967) The newborn skull: the diagnosis of fracture. Am J Roentgenol Radium Ther Nucl Med 100(1):92-99

2. Weir P, Suttner NJ, Flynn P, McAuley D (2006) Normal skull suture variant mimicking intentional injury. BMJ 332(7548):1020-1021

3. Franken EA Jr (1969) The midline occipital fissure: diagnosis of fracture versus anatomic variants. Radiology 93(5):1043-1046

4. Allen WE 3rd, Kier EL, Rothman SL (1973) Pitfalls in the evaluation of skull trauma. A review. Radiol Clin N Am 11(3):479-503

5. Nakahara K, Miyasaka Y, Takagi H, Kan S, Fujii K (2003) Unusual accessory cranial sutures in pediatric head trauma - case report. Neurol Med Chir 43(2):80-81
6. Meservy CJ, Towbin R, McLaurin RL, Myers PA, Ball W (1987) Radiographic characteristics of skull fractures resulting from child abuse. Am J Roentgenol 149(1):173-175

7. Hobbs CJ (1984) Skull fracture and the diagnosis of abuse. Arch Dis Child 59(3):246-252

8. Kleinman PK, Spevak MR (1992) Soft tissue swelling and acute skull fractures. J Pediatr 121(5):737-739

9. Fernando S, Obaldo RE, Walsh IR, Lowe LH (2008) Neuroimaging of nonaccidental head trauma: pitfalls and controversies. Pediatr Radiol 38(8):827-838

10. Nakahara K, Utsuki S, Shimizu S, Iida H et al (2006) Age dependence of fusion of primary occipital sutures: a radiographic study. Childs Nerv Syst 22(11):1457-1459

11. Kemp AM, Butler A, Morris S, Mann M et al (2006) Which radiological investigations should be performed to identify fractures in suspected child abuse? Clin Radiol 61(9):723736

12. Sty JR, Starshak RJ (1983) The role of bone scintigraphy in the evaluation of the suspected abused child. Radiology 146(2):369375 